\title{
Management of acute agitation in psychosis: an evidence-based approach in the USA ${ }^{\dagger}$
}

\author{
Justin J. Schleifer
}

\begin{abstract}
SUMMARY
Agitation in psychiatric settings, particularly in psychosis, presents a staggering challenge for clinicians, who must both manage the patient's acute symptoms and simultaneously make an accurate diagnosis. Too often, the management of the former confounds the latter. Patients are very often sedated medically, which masks their underlying condition, rendering accurate diagnosis delayed and inherently difficult. Significant data are available regarding both pharmacological and non-pharmacological interventions for agitation that maximise symptom control while minimising confounding side-effects. In this article, a review of the historical evolution of agitation management in psychotic illness is presented, followed by an evidence-based clinical guideline for managing agitation in psychosis in the USA.
\end{abstract}

\section{DECLARATION OF INTEREST}

None.

Acute agitation is common in psychotic illness, as schizophrenia, schizoaffective disorder and bipolar I disorder all present at some time with a high incidence of agitation. However, agitation is a term poorly defined and often misused by healthcare professionals. As a result of the lack of consensus, agitation is often inappropriately used interchangeably with the terms anxiety, aggression, hyperactivity, problem or disruptive behaviour, and non-purposeful behaviour. Attempts to formalise the meaning of agitation in psychiatry and avoid subjectivity in usage resulted in definitions such as:

- excess motor or verbal activity (Citrome 2004a);

- inappropriate verbal, vocal or motor activity not judged to be directly related to apparent needs (Cohen-Mansfield 1986);

- a transnosological syndrome that describes a state of poorly organised and aimless psychomotor activity stemming from physical or mental unrest, with motor restlessness and heightened responsivity to stimuli hallmark features (Lindenmayer 2000).
However, despite the multitude of formal definitions, the vagary and subjectivity of terms such as 'judged' (used in the second definition above) persisted, and a uniform definition could not be reached.

\section{Assessment scales}

Several scales have been developed to provide standardisation of agitation assessment, including, but not limited to, the Overt Agitation Severity Scale (Yudofsky 1997) and the Agitated Behavior Scale (Corrigan 1989), which are used in the context of traumatic brain injury, and the Positive and Negative Syndrome Scale, Excited Component (PANSS-EC; Kay 1987), used in the context of psychotic illness. These scales tend to conceptualise agitation on a spectrum, ranging from anxiety to aggression, and reflecting the three major components present in most definitions of agitation: strong emotion, excessive motor/vocal behaviour, and inappropriate or non-purposeful motor/vocal behaviour (Citrome 2004a). Anxiety, at one end of the spectrum, as defined by DSM-IV (American Psychiatric Association 1994), entails subjective symptoms manifested through a variety of somatic complaints, including distractibility, nervousness and difficulty concentrating. At the other end of the spectrum, aggression is more consistent with verbal abuse, verbal and physical threats, and threats of violence (Ness 2000). In some cases, agitation may even manifest as explicit violent behaviour directed at others (Kopecky 1998).

\section{Evolution of management methods}

In the USA, as in other countries, early efforts at managing agitation were focused on physically restraining and/or sedating the patient, a form of 'chemical restraint' - generating a stuporous or even unconscious state in an agitated patient (Wise 2000). Rather than addressing the source of agitation, sedation merely masked it. This masking effect hindered not only agitation management but also diagnostic efforts. Sedation may be mistaken for negative symptoms and/or cognitive
Justin J. Schleifer is currently a psychiatry resident at Brown University-Alpert Medical School. $\mathrm{He}$ is not an emergency room psychiatrist and has based this article entirely on a comprehensive review of the published literature, free from biases of current prescription practices or anecdotal evidence. Correspondence Dr Justin Schleifer, Department of Psychiatry and Human Behavior, Box G-BH, Brown University, Providence, RI 02912, USA. Email: Justin_Schleifer@Brown.edu

tFor a commentary on this article see 101-103, this issue. 
deficits (Miller 2004), compromising assessment and diagnosis, and may also contribute to nonadherence to medication because of patients' negative feelings about taking it (Citrome 2004a).

Agitation management has evolved significantly, with a strong move away from physical and 'chemical' restraints that risk physically injuring (Buckley 2003) or over-sedating patients (Downey 2007). Nevertheless, these restraint methods continue to be used in about $60 \%$ of emergency departments throughout the USA (Downey 2007).

\section{The introduction of antipsychotics and rapid tranquillisation}

The use of typical antipsychotics in agitation management brought a respite from the overly sedating benzodiazepines and barbiturates that effectively kept patients asleep, obviating the need to deal with their agitated behaviour directly. With typical antipsychotics, the sources of agitation could be directly targeted rather than masked. Antipsychotics provided a mechanism of treating the underlying cause of agitation, mainly psychosis, thus calming the patient while reducing unnecessary and unwanted sedation (Wise 2000).

As in the UK, rapid tranquillisation was introduced. Described as 'the use of psychotropic medication to control agitated, threatening or destructive psychotic behaviour' (Pereira 2005), such tranquillisation offered calming without sedation (McAllister-Williams 2002).

Unfortunately, the typical antipsychotics brought with them significant adverse effects such as movement disorders and cardiac complications, including the risk of sudden cardiac death (Abdelmawla 2006).

In 2002, with the licensing in the USA of the first fast-acting intramuscular atypical antipsychotic (ziprasidone), it became possible to calm an agitated patient rapidly by targeting the underlying source of agitation, with less sedation and without the unpleasant, unnecessary and potentially fatal adverse effects more commonly seen with typical antipsychotics. The atypicals have been proven to be at least as efficacious as the typicals in reducing agitation and other symptoms of psychosis, but with a much reduced risk of medication-induced movement disorders (Canas 2007). Consequently, atypical antipsychotics have been promoted to first-line choices in the treatment of agitation in acute psychotic disorders (Mohr 2005).

\section{Modern management of acute agitation}

Consensus guidelines (Expert Consensus Panel for Behavioral Emergencies 2005) now indicate that clinicians should aim to calm rather than sedate acutely agitated patients (Battaglia 2003). The ultimate goal of management is more than just tranquillisation: it is to defuse the state of hyperarousal as rapidly and safely as possible and to restore the patient to 'optimal self-regulatory functioning' (Citrome 2004a).

\section{Non-pharmacological interventions}

In the UK, the National Institute for Health and Clinical Excellence (NICE) emphasises the importance of non-pharmacological interventions in managing agitation, recommending that rapid tranquillisation (also known as urgent sedation) be used only 'in situations requiring the rapid control of agitation, aggression or excitement ... when other less coercive techniques of calming ... such as verbal de-escalation ... have failed' (National Collaborating Centre for Nursing and Supportive Care 2005: p. 27).

In both the USA and the UK, the primary concern when first approaching an agitated patient is the safety of the patient and those nearby. For this reason, isolation of the patient from others while the crisis is contained is crucial (Wise 2000). Stimulation from radio, television and so on may also contribute to an agitated state and should be minimised. Verbal one-on-one interaction (de-escalation) has been demonstrated to reduce anxiety and help patients regain control and should be enacted early in management (Fisher 1994).

In the USA, the Joint Commission on Accreditation of Healthcare Organizations (JCAHO) mandated in 2000 that restraint and/or seclusion can only be used in an emergency, when other attempts to manage agitation have failed and there is imminent risk of harm to a patient or others (Wise 2000). Therefore, in the USA seclusion and restraints are considered treatments of last resort and should be used as such (Buckley 2003). In the UK, however, the NICE guidelines recommend seclusion if rapid tranquillisation is contraindicated but they note that it should not be considered a therapeutic intervention; rather, it should be seen as allowing a period of calming for the patient.

The UK is in agreement with the USA in recommending that physical restraint (which NICE calls physical intervention) be used only as a last resort, when there is a real possibility of significant harm if it is not used. In most situations, the restraint should be limited to manual holding: mechanical devices such as belts or handcuffs should not be used, except in exceptional circumstances, usually within high-security settings (National Collaborating Centre for Nursing and Supportive Care 2005: p. 26). 


\section{Pharmacological interventions (rapid tranquillisation)}

Pharmacological management of acute agitation has been typically limited to four classes of medication: barbiturates, benzodiazepines, typical antipsychotics and, more recently, atypical antipsychotics. For years, barbiturates and then typical antipsychotics with or without benzodiazepines (most commonly, intramuscular administration of $5 \mathrm{mg}$ haloperidol and $2 \mathrm{mg}$ lorazepam) have been the mainstay of treatment (Bellnier 2002). However, 93\% of patients prefer oral formulations during a behavioural emergency, perceiving parenteral administration as coercive and abusive (Altamura 2003). Recent literature has shown that, for patients willing to take them, oral atypical antipsychotics are at least as effective as intramuscular typical antipsychotics in acute psychotic agitation (Currier 2006a). They should therefore be the first-line method of pharmacological administration (Mohr 2005).

In 2005, the US Journal of Psychiatric Practice published a supplement on the treatment of behavioural emergencies as part of its Expert Consensus Guidelines Series (Expert Consensus Panel for Behavioral Emergencies 2005). It was generated from responses to a survey by 48 of 50 invited leading American experts in psychiatric emergency medicine. The publication received financial support in the form of grants from AstraZeneca, Janssen and Pfizer but, to reduce any possible bias, the experts contacted were not aware of this. The survey resulted in the following recommendation for first-line treatment of acute schizophrenia or mania: oral olanzapine, oral risperidone, or haloperidol plus a benzodiazepine (Expert Consensus Panel for Behavioral Emergencies 2005).

Oral disintegrating (orodispersible) formulations that dissolve in seconds prevent patients from hiding tablets in their mouths and subsequently spitting them out; they are bioequivalent to regular tablets (Van Schaick 2003). However, the efficacy of oral formulations is limited by patients' cooperation in taking them, which is problematic in many severely agitated patients. One literature review found that severe agitation could be managed with oral formulations alone in only $55 \%$ of cases (De Fruyt 2004).

The NICE guidelines recommend that vital signs be monitored after rapid tranquillisation and that pulse oximeters be available. Blood pressure, pulse, temperature, respiratory rate and hydration should be recorded regularly (National Collaborating Centre for Nursing and Supportive Care 2005: p. 102).

\section{TABLE 1 Benzodiazepines for acute agitation}

\begin{tabular}{|llcc|}
\hline Drug (formulation) & Key characteristics & $\begin{array}{c}\text { Onset } \\
\text { of action }\end{array}$ & Half-life \\
\hline Clonazepam (oral/IM) & $\begin{array}{l}\text { Not recommended: limited } \\
\text { efficacy and may increase } \\
\text { psychosis or agitation }\end{array}$ & $20-60 \mathrm{~min}$ & $19-50 \mathrm{~h}$ \\
\hline Diazepam (oral/IM) & $\begin{array}{l}\text { Long-lasting effect } \\
\text { Prolonged sedation } \\
\text { IM not recommended }\end{array}$ & $0.5-2 \mathrm{~h}$ (oral) & $30-60 \mathrm{~h}$ \\
\hline Lorazepam (oral/IM) & $\begin{array}{l}\text { Preferred benzodiazepine } \\
\text { Complete, rapid intramuscular } \\
\text { absorption }\end{array}$ & $1-1.5 \mathrm{~h}$ & $12-15 \mathrm{~h}$ \\
\hline Midazolam (oral/IM) & $\begin{array}{l}\text { Effective for motor agitation } \\
\text { Short-acting } \\
\text { Greater sedation }\end{array}$ & $\begin{array}{l}5-15 \mathrm{~min} \text { (IM) } \\
10-30 \mathrm{~min} \text { (oral) }\end{array}$ & $1-4 \mathrm{~h}$ \\
\hline
\end{tabular}

$\mathrm{IM}$, intramuscular.

The most commonly used and recommended pharmacological agents for the management of agitation in psychosis are reviewed in the following sections.

\section{Benzodiazepines}

Benzodiazepines (Table 1) produce anti-agitation effects via modulation of $\gamma$-aminobutyric acid (GABA) neurotransmission and evidence suggests that they are at least as effective as - and at higher doses superior to - typical antipsychotics in agitation treatment (Foster 1997; Allen 2000; Battaglia 2005). Benzodiazepines have significantly fewer extrapyramidal side-effects than typical antipsychotics, but they can cause respiratory depression, ataxia and excessive sedation (Allen 2000; Battaglia 2005). The sedative effect of benzodiazepines is the major limiting factor in their use for managing agitation: as discussed above, sedation should not be the endpoint of management and may hinder diagnosis.

Lorazepam is the most popular benzodiazepine for agitation, owing to its complete and rapid intramuscular absorption, onset within 60-90 minutes, half-life of 12-15 hours, and 8-10 hour duration of action (Battaglia 2005; Greenblatt 2005). Diazepam is frequently used for its long-lasting effect, but prolonged sedation of a patient is often not desirable, making shorteracting benzodiazepines such as lorazepam more attractive. Evidence for the superiority of midazolam over haloperidol for managing motor agitation is encouraging, but it is overly sedating and the majority of patients treated with midazolam fell asleep after intramuscular administration (Mendoza 1987). Clonazepam has limited efficacy in treating agitation. It may in fact increase psychosis or agitation in some individuals and is therefore not recommended (Battaglia 2005). 
a. Unless otherwise specified, the response criterion used to generate the number needed to treat (NNT) for a particular drug is based on a $40 \%$ reduction on the Positive and Negative Syndrome Scale, Excited Component (PANSS-EC) 2 hours after administration.

\section{Typical antipsychotics}

Typical antipsychotics, especially haloperidol, have been a mainstay of agitation treatment. They are thought to produce anti-agitation effects by inhibition of dopaminergic transmission, along with histamine and noradrenaline (norepinephrine) blockade, although the blockade mechanism has been less clearly established (Leonard 1992; Altamura 2003).

Adverse effects more commonly seen in typical antipsychotic usage include extrapyramidal symptoms of dystonia, akathisia and Parkinsonism. In addition, antipsychotics (typical and atypical) carry the risk of neuroleptic malignant syndrome. Another critical concern for antipsychotics is the increased risk of cardiac arrhythmias associated with prolongation of the QT interval.

Haloperidol is the most frequently used typical antipsychotic for the management of acute agitation and has an onset of action from 15 to 60 minutes (Battaglia 2005; National Collaborating Centre for Nursing and Supportive Care 2005). Chlorpromazine (both oral and intramuscular) is not recommended because of the hypotensive and $\mathrm{QT}_{\mathrm{c}}$ interval effects associated with its use at the doses suitable for rapid tranquillisation. Intramuscular haloperidol at $6.5 \mathrm{mg}$ yields an $\mathrm{NNT}^{\mathrm{a}}$ of 5 (95\% CI 3-11) and at $7.5 \mathrm{mg}$ an NNT of 3 (95\% CI 2-5) (Citrome 2007).

The most commonly problematic adverse effects with haloperidol are extrapyramidal symptoms, for which anticholinergics may be given as needed or prophylactically (Battaglia 2005).

Owing to its pervasive use and established efficacy in managing agitation in psychosis,

\section{TABLE 2 Atypical antipsychotics for acute agitation}

\begin{tabular}{|c|c|c|c|}
\hline Drug (formulation) & Key characteristics & $\begin{array}{l}\text { Onset } \\
\text { of action }\end{array}$ & Half-life \\
\hline Aripiprazole (oral/IM) & $\begin{array}{l}\text { Lower risk of weight gain } \\
\text { Delayed onset } \\
\text { Possible somnolence }\end{array}$ & $3-5 h$ & $75-146 h$ \\
\hline Olanzapine (oral/IM) & $\begin{array}{l}\text { Rapid onset } \\
\text { Greater sedation, somnolence, } \\
\text { weight gain } \\
\text { Caution in hypotensive } \\
\text { patients - avoid parenteral } \\
\text { benzodiazepines }\end{array}$ & $15-45 \min$ & $21-54 h$ \\
\hline Quetiapine (oral) & Useful for aggressive patients & $1.5 \mathrm{~h}$ & $6 \mathrm{~h}$ \\
\hline Risperidone (oral) & $\begin{array}{l}\text { Not available in fast-acting IM } \\
\text { formulation }\end{array}$ & $1-2 h$ & $20-24 h$ \\
\hline Ziprasidone (oral/IM) & $\begin{array}{l}\text { Lower risk of weight gain } \\
\text { Caution in patients with renal } \\
\text { impairment } \\
\text { Possible OT interval } \\
\text { prolongation }\end{array}$ & $30-45 \min$ & $\begin{array}{l}2-5 \mathrm{~h}(\mathrm{IM}) \\
7 \mathrm{~h} \text { (oral) }\end{array}$ \\
\hline
\end{tabular}

$\mathrm{IM}$, intramuscular. haloperidol has become the gold standard against which all anti-agitation medications, including the atypical antipsychotics, are measured.

\section{Atypical antipsychotics}

Atypical antipsychotics (Table 2) are a newer development in the management of agitation. Owing to their action on serotonergic as well as dopaminergic receptors they carry an adverse risk profile distinct from that of typical antipsychotics, with less dysphoria, akathisia and extrapyramidal side-effects (Battaglia 2005). Interestingly, some patients have even been reported to request an additional dose of an atypical antipsychotic when being treated for an agitated state in the emergency room (Preval 2005).

Atypicals are available in both oral and intramuscular formulations. Intramuscular ziprasidone was made available in the USA in 2002, with indications for agitation associated with schizophrenia. Intramuscular olanzapine followed in 2004 for agitation associated with schizophrenia and bipolar mania. Finally, in 2006, intramuscular aripiprazole became available for agitation associated with schizophrenia and bipolar mania (Citrome 2007).

The consensus guidelines mentioned above (Expert Consensus Panel for Behavioral Emergencies 2005) currently recommend atypical antipsychotics as first-line agents for acute agitation in schizophrenia, although evidence of atypical antipsychotic efficacy in managing agitation in bipolar I disorder has also been established (Meehan 2001; Zimbroff 2007). Olanzapine and risperidone are both available in disintegrating oral tablets and are therefore optimal as first-line interventions for patients who will take them.

\section{Ziprasidone}

Ziprasidone primarily acts as a dopamine/ serotonin antagonist. It has low potential for causing extrapyramidal symptoms and was the first atypical antipsychotic made available in rapidacting intramuscular formulation, with an onset of action of 30-45 minutes (Battaglia 2005).

In the USA, the drug was approved for acute agitation in schizophrenia on the basis of two double-blind trials (Daniel 2001; Lesem 2001). Ziprasidone (10-20 mg) yields an NNT of 3 (95\% CI 2-4) with the response criterion defined as at least a 2-point reduction in the Behavioural Activity Rating Scale, 2 hours after injection (Citrome 2007). Incidence of movement disorders, including akathisia, dystonia and extrapyramidal symptoms, is < $4 \%$ compared with $12-38 \%$ for haloperidol (Mendelowitz 2004). 
Safety concerns with intramuscular ziprasidone include caution when treating patients with renal impairment, as the cyclodextrin excipient is cleared by renal filtration. Ziprasidone is also known to cause greater dose-related QT interval prolongation than haloperidol, olanzapine and risperidone. Owing to fatal arrhythmias associated with QT prolongation caused by other drugs, ziprasidone is contraindicated in patients with a known history of QT prolongation, recent myocardial infarction or uncompensated heart failure (Glassman 2001; Pfizer 2009).

\section{Olanzapine}

Olanzapine, which acts on multiple receptors, has an onset of action of 15-45 minutes (Battaglia 2004). Three placebo-controlled trials that showed the superiority of $2.5-10 \mathrm{mg}$ of intramuscular olanzapine over placebo and its non-inferiority to $7.5 \mathrm{mg}$ intramuscular haloperidol provided the basis for olanzapine use in acute agitation associated with schizophrenia (Wright 2001; Citrome 2007). However, placebo-controlled trials have indicated a higher incidence of sedation compared with placebo, with somnolence present in $29 \%$ of patients compared with $13 \%$ in the placebo arm (Eli Lilly 2006). Olanzapine can be as sedating as haloperidol or lorazepam (Currier 2004a). In a trial involving patients with schizophrenia, the NNT for $10 \mathrm{mg}$ olanzapine was 3 (95\% CI 2-3). In bipolar I mania, 10 mg olanzapine also yielded an NNT of 3 (95\% CI 2-5) (Meehan 2001). Intramuscular olanzapine is as efficacious as haloperidol and has significant advantages in terms of extrapyramidal symptoms: Parkinsonism was avoided in 1 in 7 patients, acute dystonia in 1 in 14 , and anticholinergic prescriptions were avoided in 1 in 7 patients (Tulloch 2004; Citrome 2007).

Safety concerns related to olanzapine include hypotension, bradycardia with or without hypotension, tachycardia and syncope. Consequently, parenteral benzodiazepines should be avoided in patients simultaneously receiving intramuscular olanzapine (Eli Lilly 2008). The number needed to harm (NNH) was significant for hypotension, at 50 (95\% CI 30-154) compared with placebo (Citrome 2007).

If possible, an oral formulation should be given at a loading dose of 5 to $20 \mathrm{mg}$, as this has been shown to be safe and effective at quickly calming acutely agitated psychotic patients (Karagianis 2001). Oral olanzapine can be used alone or with oral lorazepam, which has been shown to be as effective as oral haloperidol plus lorazepam in reducing acute agitation (Escobar 2008). Oral olanzapine is uniquely advantageous in its efficacy as a monotherapy in both emergency rooms and psychiatric units, which not only contributes to medication adherence and a positive doctorpatient relationship, but also avoids the adverse effects often seen in transition from intramuscular to oral medications (Escobar 2008).

\section{Risperidone}

Risperidone is a potent dopamine antagonist with high affinity for $\mathrm{D}_{2}$ receptors and action on multiple serotonergic receptors. Despite the fact that risperidone is not currently available in a fast-acting intramuscular formulation, it has been found to be effective in managing agitation in patients willing to take oral medication. Earlier studies found that oral risperidone plus oral lorazepam was tolerable and comparable to intramuscular haloperidol plus lorazepam for short-term treatment of agitated psychosis in patients who accept oral medications (Currier 2000, 2001, 2004b). A later study found that oral risperidone plus oral lorazepam was more successful at managing acute psychotic agitation 2 hours after administration when compared with intramuscular conventional antipsychotics such as haloperidol and zuclopenthixol (Lejeune 2004). A meta-analysis found that risperidone yielded superior efficacy to haloperidol in managing hostility and aggression in patients with schizophrenia (Aleman 2001).

\section{Aripiprazole}

Aripiprazole differs pharmacologically from the other atypical antipsychotics in its partial agonism at dopamine $\mathrm{D}_{2}$ and serotonin $5-\mathrm{HT}_{1 \mathrm{~A}}$ receptors and antagonism at $5-\mathrm{HT}_{2 \mathrm{a}}$ receptors (Burris 2002). In at least three randomised, double-blind, placebo-controlled studies it was found to be efficacious, safe and tolerable in treating agitation in patients with bipolar I disorder, schizophrenia or schizoaffective disorder (Andrezina 2006; Currier 2007; Tran-Johnson 2007). In one of these studies (Andrezina 2006) the efficacy of $9.75 \mathrm{mg}$ intramuscular aripiprazole was established $v$. $6.5 \mathrm{mg}$ intramuscular haloperidol. Aripiprazole demonstrated rapid and effective control of agitation in schizophrenia and schizoaffective disorder with a significant reduction in events involving extrapyramidal side-effects $(1.7 \%$ v. $12.6 \%)$ (Citrome 2007). A dose of $9.75 \mathrm{mg}$ intramuscular aripiprazole was shown to be the most effective and best tolerated from a range of 1, 5.25, 9.75 and $15 \mathrm{mg}$ (Glassman 2001). In schizophrenia, $9.75 \mathrm{mg}$ aripiprazole has an NNT of 6 (95\% CI 4-16); in bipolar mania, $10 \mathrm{mg}$ and $15 \mathrm{mg}$ aripiprazole have an NNT of 4 (95\% CI 3-10) (Citrome 2007). Aripiprazole has been associated with reduced 
sedation compared with placebo (Citrome 2007), but somnolence has been reported to be marginally higher than with placebo (Bristol-Myers Squibb 2003). Compared with those on haloperidol, patients on aripiprazole had a 10\% lower risk of extrapyramidal side-effects (Citrome 2007).

\section{Quetiapine}

In emergency room psychiatric settings, quetiapine at doses ranging from 300 to $800 \mathrm{mg} /$ day has been shown to be as effective as olanzapine and risperidone, and better tolerated than haloperidol (Villari 2008), despite preliminary data that suggested it to be less efficacious than olanzapine and risperidone (Raja 2003). Relative to haloperidol, quetiapine at doses ranging from 150 to $750 \mathrm{mg}$ has direct calming effects on agitation independent of its effect in improving psychosis. It demonstrated a reduction in both hostility and agitation among patients experiencing an acute exacerbation of schizophrenia (Chengappa 2003). In patients with aggressive psychosis, it has been reported to reduce overall aggression within the first 24 hours of treatment, aggression towards others by $83 \%$ within 2 days of treatment, and sustained reduction in overall aggression over 5 days of treatment (Ganesan 2005).

\section{The transition from intramuscular to oral formulations}

Consensus guidelines recommend switching from intramuscular medication to oral formulations when managing long-term agitation subsequent to acute episodes (Expert Consensus Panel for Behavioral Emergencies 2005). This transition, although recommended, can engender adverse effects. Such effects are more common with typical than with atypical antipsychotics. In a comparison of haloperidol (without concomitant anticholinergic medication) and olanzapine, dystonia affected $4.3 \%$ v. $0 \%(P=0.026)$ and akathisia affected $5.2 \%$ v. $0 \%(P=0.013)$ of participants on transition from intramuscular to oral formulations of the respective drugs (Wright 2003). The same study reported that the initial alleviation of agitation was sustained in the transition. The absence of spontaneously reported acute dystonia in the olanzapine-treated patients over several days of continued oral treatment demonstrated its superior extrapyramidal side-effect safety profile compared with haloperidol.

Haloperidol has demonstrated increased rates of events involving extrapyramidal side-effects in transition compared with aripiprazole and ziprasidone and it frequently requires concomitant administration of anticholinergic medications
(Daniel 2004; Citrome 2007). One of the major benefits of using the more expensive atypical antipsychotics is the obviation of anticholinergic use both prophylactically and acutely (Raja 2001).

\section{Comparison of atypical antipsychotics}

Relative to placebo, the atypical antipsychotics demonstrate notable efficacy in the management of acute agitation in the populations discussed above. Additionally, they significantly reduce the incidence of movement disorders and sedation compared with older treatments. However, there are significant differences between the atypical antipsychotics that should help guide the decisionmaking process regarding their use. Unfortunately, only a few head-to-head comparisons of the atypicals have been conducted (see below). Most of the comparisons of efficacy have been generated relative to respective comparisons with placebo and older treatments, including haloperidol and lorazepam.

Regarding US Food and Drug Administration (FDA) indications (analogous to 'licenses' in the UK), ziprasidone is indicated for agitation in schizophrenia only, while olanzapine and aripiprazole are the only atypical antipsychotics discussed with indications for agitation associated with either schizophrenia or bipolar I mania. Neither risperidone nor quetiapine, despite their established efficacy, currently have specific indications for the treatment of agitation in schizophrenia or bipolar I mania. However, the absence of specific indications for agitation should not necessarily dissuade the provider from choosing a particular agent for the management of agitation, as the process of obtaining additional indications for an already approved medication is both lengthy and costly.

\section{Efficacy}

Earlier research indicated that olanzapine is the most effective oral atypical antipsychotic as, unlike risperidone, it does not require adjunctive oral lorazepam (Currier 2001). However, a more recent trial compared oral risperidone solution monotherapy with oral olanzapine tablets and found equal efficacy in successfully reducing acute agitation (Hatta 2008). One ambitious study compared five atypical antipsychotics with each other and demonstrated superior efficacy of olanzapine and risperidone over quetiapine, ziprasidone and aripiprazole for the acute treatment of schizophrenia, schizoaffective disorder or schizophreniform disorder (McCue 2006). Another study, conducted in an emergency room, found olanzapine and risperidone to be superior in 
efficacy to quetiapine in treating acute psychosis (Raja 2003). In a head-to-head trial involving acutely ill patients with schizophrenia, olanzapine and aripiprazole produced similar improvement in agitation and positive symptoms during the first 5 days of in-patient treatment (Kinon 2008).

The literature thus suggests that the five atypical antipsychotics discussed here have all demonstrated efficacy in managing agitation in psychosis. However, since olanzapine and risperidone have demonstrated superiority in monotherapy and are both available in oral formulations, there may be an advantage in their use at the onset of treatment.

\section{Safety}

Ziprasidone should be used with caution in patients with renal impairment and is contraindicated in patients with cardiac impairment, as mentioned above, and in patients taking medications that also prolong the QT interval. Olanzapine has a significant risk of hypotension and should be used with caution in patients with conditions that predispose to hypotension. Parenteral benzodiazepines with intramuscular olanzapine or aripiprazole should be used only if essential and with caution because of the increased risk of excessive sedation and cardiorespiratory depression. Since aripiprazole and olanzapine have been shown to be effective in monotherapy this should not be a frequent problem. In a small open-label study of quetiapine, orthostasis was present in $40 \%$ of patients at $100-200 \mathrm{mg}$ doses (Currier 2006a).

\section{Antipsychotics and the risk of sudden cardiac death}

Cardiovascular causes account for $5 \%$ of sudden and unexpected deaths in patients with schizophrenia. Prospective studies have indicated that patients with QT interval prolongation beyond $500 \mathrm{~ms}$ are at an increased risk of arrhythmias (e.g. ventricular tachycardia) and torsades de pointes (Abdelmawla 2006). Ziprasidone has been shown to increase the QT interval by $15-35 \mathrm{~ms}$, and haloperidol, quetiapine and olanzapine do so by 5-15 ms (Abdelmawla 2006). Antipsychotics affect the QT interval via blockade of various cardiac ion channels. In particular, blocking of potassium channels is responsible for slowing repolarisation, which leads to prolongation of the QRS interval and ultimately extension of the QT interval (DuBuske 1999). Prospective cohort trials of antipsychotic use reported relative risks of sudden death of 2.06 over 4 years (Montout 2002) and 2.39 over 5 years (Ray 2001). These effects tend to be dose-dependent and are of greatest concern in patients who take large overdoses (Abdelmawla 2006). However, in cases of emergency use for the management of agitation (rapid tranquillisation), several large trials involving over 1500 patients given haloperidol, ziprasidone, olanzapine, midazolam or a haloperidol-promethazine mix reported no deaths or serious cardiovascular events (TREC Collaborative Group 2003; Citrome 2004b). Despite the relatively low risk related to antipsychotics in emergency (rapid tranquillisation) settings, the patient's medical history and baseline electrocardiogram can help guide antipsychotic choice; if a patient has risk factors for sudden cardiac death or QT prolongation, haloperidol or olanzapine would be preferred to quetiapine and ziprasidone, which are known to cause a greater prolongation (Abdelmawla 2006).

\section{Clinical guidelines}

Figure 1 outlines the procedure to follow in managing acute agitation, and medication choices if verbal de-escalation is unsuccessful.

\section{Ensuring safety}

The first step should be to maximise safety for all those present: the individual should be isolated from other patients (Marder 2006) and distractions such as TV and radio should be switched off (Citrome 2004a).

\section{Verbal de-escalation}

Staff should present a non-aggressive show of force and demonstrate that they are in control of the situation (Citrome 2004a). They should convey calm, empathy, concern for the patient's well-being and assurances that the patient is safe (Petit 2005). The patient should be allowed to express their feelings and concerns, and should not be shouted at or threatened (Citrome 2004a). Simultaneously, the patient should be assessed for changes in medical condition, possible substance intoxication and development of akathisia.

\section{Pharmacotherapy}

Medication may be initiated alone or as an adjunct to unsuccessful or only mildly successful verbal de-escalation, and agent(s) must be selected with consideration for aetiology of the agitation and diagnosis (Petit 2005). If the patient is willing and able to take them, oral atypical antipsychotics should be the drug of first choice.

In agitation secondary to substance intoxication, evidence-based guidelines recommend treatment based on underlying aetiology, if known (Allen 2000). This recommendation is very important as certain drugs of misuse have anticholinergic 


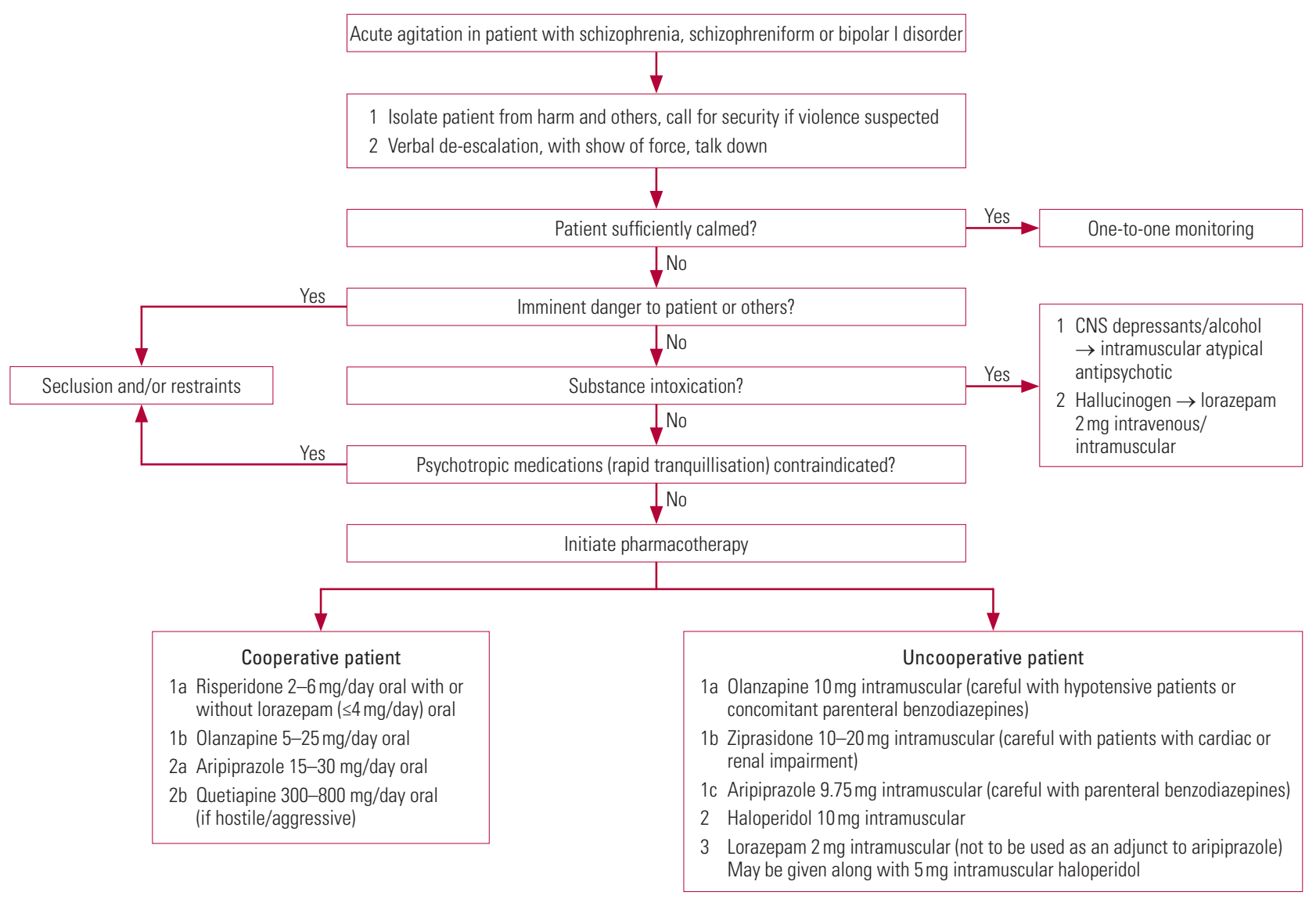

Management of psychotic agitation. Medications are listed in numerical order of preferred use, given demonstrated efficacy while minimising sedation. Medications listed as a, b, c are comparable options with similar efficacy and should be selected on the basis of the patient's medical profile. CNS, central nervous system.

properties and psychotropic drugs with anticholinergic effects may potentiate the toxicity of the substance. Therefore, if anticholinergic delirium is suspected in an agitated patient, benzodiazepines are the first-line choice of pharmacotherapy and antipsychotics should be avoided (Citrome 2004a; Petit 2005).

\section{Seclusion and restraint}

Seclusion and physical restraint should be considered only as a last resort, if behavioural modifications and pharmacotherapy fail or are contraindicated, and/or if patients are a danger to themselves or others.

\section{Conclusions}

The management of agitation in the context of psychosis presents a challenge that is as multifaceted as it is prevalent. Over the past decade, there have been significant contributions to the research of agitation which now afford clinicians an extensive assortment of treatment options. However, rather than using the most current, evidence-based practices to tailor customised treatment plans for their agitated patients, clinicians often fall back on 'what works' (in their experience). The goal of this article was to provide a thorough and concise review of the literature to enable clinicians to effectively manage agitation with minimal detriment to the diagnostic process, and, most importantly, to the patient.

\section{References}

Abdelmawla N, Mitchell A (2006) Sudden cardiac death and antipsychotics. Part 1: Risk factors and mechanisms. Advances in Psychiatric Treatment 12: 35-44.

Aleman A, Kahn RS (2001) Effects of the atypical antipsychotic risperidone on hostility and aggression in schizophrenia: a meta-analysis of controlled trials. European Neuropsychopharmacology 11: 289-93.

Allen MH (2000) Managing the agitated psychotic patient: a reappraisal of the evidence. Journal of Psychiatry 61 (suppl 14): 11-20.

Altamura AC, Sassella F, Santini A, et al (2003) Intramuscular preparations of antipsychotics: uses of relevance in clinical practice. Drugs 63: 493-512.

American Psychiatric Association (1994) Diagnostic and Statistical Manual of Mental Disorders (4th edn) (DSM-IV). APA.

Andrezina R, Josiassen RC, Marcus RN, et al (2006) Intramuscular aripiprazole for the treatment of acute agitation in patients with schizophrenia or schizoaffective disorder: a double-blind, placebo-controlled comparison with intramuscular haloperidol. Psychopharmacology (Berlin) 188: 281-92.

Battaglia J, Lindborg SR, Alaka K, et al (2003) Calming versus sedative effects of intramuscular olanzapine in agitated patients. American Journal of Emergency Medicine 21: 192-8. 
Battaglia J (2004) Intramuscular olanzapine: treating acute agitation in psychosis and bipolar mania. Current Psychiatry 3: 76-8.

Battaglia J (2005) Pharmacologic management of acute agitation. Drugs 65: $1207-22$

Bellnier TJ (2002) Continuum of care: stabilizing the acutely agitated patient. American Journal of Health-system Pharmacy 59 (suppl 5): s12-8.

Bristol-Myers Squibb (2003) Aripiprazole (Abilify) Package Insert. BristolMyers Squibb.

Buckley PF, Noffsinger SG, Smith DA, et al (2003) Treatment of the psychotic patient who is violent. Psychiatric Clinics of North America 26: 231-72.

Burris KD, Molski TF, Xu C, et al (2002) Aripiprazole, a novel antipsychotic is a high-affinity partial agonist at human dopamine D2 receptors. Journal of Pharmacology and Experimental Therapeutics 302: 381-9.

Canas F (2007) Management of agitation in the acute psychotic patient: efficacy without excessive sedation. European Neuropsychopharmacology 17 (suppl 2): s108-14

Chengappa KNR, Goldstein JM, Greenwood M, et al (2003) A post hoc analysis of the impact on hostility and agitation of quetiapine and haloperidol among patients with schizophrenia. Clinical Therapeutics 25 : 530-41.

Citrome L (2004a) New treatments for agitation. Psychiatric Quarterly 75: $197-213$

Citrome L, Brook S, Warrington L, et al (2004b) Ziprasidone versus haloperidol for the treatment of agitation. Annals of Emergency Medicine 44 (suppl): S22

Citrome L (2007) Comparison of intramuscular ziprasidone, olanzapine, or aripiprazole for agitation: a quantitative review of efficacy and safety. Journal of Clinical Psychiatry 68: 1876-85

Cohen-Mansfield J (1986) Agitated behavior in the elderly: a conceptual review. Journal of the American Geriatrics Society 34: 711-21.

Corrigan JD (1989) Development of a scale for assessment of agitation following traumatic brain injury. Journal of Clinical and Experimental Neuropsychology 11: 261-77

Currier GW, Allen MH (2000) Physical and chemical restraint in the psychiatric emergency service. Psychiatric Services 51: 717-9.

Currier GW, Simpson GM (2001) Risperidone liquid concentrate and oral lorazepam versus intramuscular haloperidol and intramuscular lorazepam for treatment of psychotic agitation. Journal of Clinical Psychiatry 62 : $153-7$.

Currier G, Allen MH, Bunney EB, et al (2004a) Novel therapies for treating acute agitation. Journal of Emergency Medicine 27 (suppl 1): S13-8.

Currier GW, Chou JCY, Feifel D, et al (2004b) Acute treatment of psychotic agitation: a randomized comparison of oral treatment with risperidone and lorazepam versus intramuscular treatment with haloperidol and lorazepam. Journal of Clinical Psychiatry 65: 386-94.

Currier G, Trenton AJ, Walsh PG, et al (2006a) A pilot, open-label safety study of quetiapine for treatment of moderate psychotic agitation in the emergency setting. Journal of Psychiatric Practice 12: 223-8.

Currier GW, Medori (2006b) Orally versus intramuscularly administered antipsychotic drugs in psychiatric emergencies. Journal of Psychiatric Practice 12: 30-40.

Currier GW, Citrome LL, Zimbroff DL, et al (2007) Intramuscular aripiprazole in the control of agitation. Journal of Psychiatric Practice 3: 159-69

Daniel DG, Potkin SG, Reeves KR, et al (2001) Intramuscular (IM) ziprasidone $20 \mathrm{mg}$ is effective in reducing acute agitation associated with psychosis: a double-blind, randomized trial. Psychopharmacology (Berlin) 155: 128-34.

Daniel DG, Zimbroff DL, Swift RH, et al (2004) The tolerability of intramuscular ziprasidone and haloperidol treatment and the transition to oral therapy. International Clinical Psychopharmacology 19: 9-15.

De Fruyt, Demyttenaere K (2004) Rapid tranquilization: new approaches in the emergency treatment of behavioral disturbances. European Psychiatry 19: $243-9$
Downey LV, Zun LS, Gonzales SJ (2007) Frequency of alternative to restraints and seclusion and uses of agitation reduction techniques in the emergency department. General Hospital Psychiatry 29: 470-4.

DuBuske LM (1999) Second-generation antihistamines: the risk of ventricular arrhythmias. Clinical Therapeutics 21: 281-95.

Eli Lilly (2006) Olanzapine (Zyprexa) US Prescribing Information. Eli Lilly.

Eli Lilly (2008) Highlights of Prescribing Information: Zyprexa (Olanzapine) Tablets, Zyprexa Zydis (Olanzapine) Orally Disintegrating Tablets, Zyprexa Intramuscular (Olanzapine) for Injection. Product Information, Revised March 10, 2008. Eli Lilly (http://pi.lilly.com/us/zyprexa-pi.pdf).

Escobar R, San L, Pérez V, et al (2008) Effectiveness results of olanzapine in acute psychotic patients with agitation in the emergency room setting: results form NATURA study [in Spanish]. Actas Españolas de Psiquiatría 36: 151-7.

Expert Consensus Panel for Behavioral Emergencies (2005) The expert consensus guideline series. Treatment of behavioral emergencies 2005. Journal of Psychiatric Practice 11 (suppl 1): 5-108.

Fisher WA (1994) Restraint and seclusion: a review of the literature. American Journal of Psychiatry 15: 1584-91.

Foster S, Kessel J, Berman ME, et al (1997) Efficacy of lorazepam and haloperidol for rapid tranquilization in a psychiatric emergency room setting. International Clinical Psychopharmacology 12: 175-9.

Ganesan ML, Bilsker D, Khanbhai I (2005) Effectiveness of quetiapine for the management of aggressive psychosis in the emergency psychiatric setting: a naturalistic uncontrolled trial. International Journal of Psychiatry in Clinical Practice 9: 199-203.

Glassman AH (2001) Antipsychotic drugs: prolonged OTc interval, Torsades de pointes, and sudden death. American Journal of Psychiatry 158: 1774-82.

Greenblatt DJ, Blaskovich PD, Nuwayser ES, et al (2005) Clonazepam pharmacokinetics: comparison of subcutaneous microsphere injection with multiple-dose oral administration. Journal of Pharmacology 45 : 1288-93.

Hatta K, Kawabata T, Yoshida K, et al (2008) Olanzapine orally disintegrating tablet vs. risperidone oral solution in the treatment of acutely agitated psychotic patients. General Hospital Psychiatry 30 : 367-71

Karagianis JL, Dawe IC, Thakur A et al (2001) Rapid tranquilization with olanzapine in acute psychosis: a case series. Journal of Clinical Psychiatry 62 (suppl 2): 12-6.

Kay SR, Fiszbein A, Opler LA (1987) The Positive and Negative Syndrome Scale (PANSS) for schizophrenia. Schizophrenia Bulletin 13: 261-76.

Kinon BJ, Stauffer VL, Kollack-Walker S, et al (2008) Olanzapine versus aripiprazole for the treatment of agitation in acutely ill patients with schizophrenia. Journal of Psychopharmacology 28: 601-7.

Kopecky HJ, Kopecky CR, Yudofsky SC (1998) Reliability and validity of the Overt Agitation Severity Scale in adult psychiatric inpatients. Psychiatric Quarterly 69: 301-23.

Lejeune J, Larmo I, Chrzanowski W, et al (2004) Oral risperidone plus oral lorazepam versus standard care with intramuscular conventional neuroleptics in the initial phase of treating individuals with acute psychosis. International Clinical Psychopharmacology 19: 259-69.

Leonard BE (1992) Fundamentals of Psychopharmacology. John Wiley \& Sons.

Lesem MD, Zajecka JM, Swift RH, et al (2001) Intramuscular ziprasidone, $2 \mathrm{mg}$ versus $10 \mathrm{mg}$, in the short-term management of agitated psychotic patients. Journal of Clinical Psychiatry 62: 12-8.

Lindenmayer $J(2000)$ The pathophysiology of agitation. Journal of Clinical Psychiatry 61 (suppl 14): 5-10.

Marder SR (2006) A review of agitation in mental illness: treatment guidelines and current therapies. Journal of Clinical Psychiatry 67 (suppl 10): 13-21.

McAllister-Williams RH, Ferrier IN (2002) Rapid tranquillisation: time for a reappraisal of options for parenteral therapy. British Journal of Psychiatry 180: 485-9.
MCO answers

$1 d \quad 2 d \quad 3 d \quad 4 d \quad 5 c$ 
McCue RE, Waheed R, Urcuyo L, et al (2006) Comparative effectiveness of second-generation antipsychotics and haloperidol in acute schizophrenia. British Journal of Psychiatry 189: 433-40.

Meehan K, Zhang F, David S, et al (2001) A double-blind, randomized comparison of the efficacy and safety of intramuscular injections of olanzapine, lorazepam, or placebo in treating acutely agitated patients diagnosed with bipolar mania. Journal of Clinical Psychopharmacology 21: 389-97.

Mendelowitz A (2004) The utility of intramuscular ziprasidone in the management of acute psychotic agitation. Annals of Clinical Psychiatry 16: $145-54$.

Mendoza R, Djenderedjian AH, Adams J, et al (1987) Midazolam in acute psychotic patients with hyperarousal. Journal of Clinical Psychiatry 48: 291-2.

Miller DD (2004) Atypical antipsychotics: sleep, sedation, and efficacy. Primary Care Companion to the Journal of Clinical Psychiatry 6 (suppl 2): 3-7.

Mohr P, Pecenák J, Svestka J, et al (2005) Treatment of acute agitation in psychotic disorders. Neuroendocrinology Letters 26: 327-35.

Montout C, Casadebaig F, Lagnaoui R, et al (2002) Neuroleptics and mortality in schizophrenia: prospective analysis of deaths in a French cohort of schizophrenic patients. Schizophrenia Research 57: 147-56.

National Collaborating Centre for Nursing and Supportive Care (2005) Violence: The Short-term Management of Disturbed/Violent Behaviour in In-Patient Psychiatric Settings and Emergency Departments (Clinical Practice Guideline 25). National Institute for Health and Clinical Excellence (http://www.nice.org.uk/nicemedia/live/10964/29719/29719.pdf).

Ness G, House A, Ness AR (2000) Aggression and violent behaviour in general practice: population based survey in the north of England. BMJ 320: $1447-8$

Pereira S, Paton C, Walkert LM, et al (2005) Treatment of acute behavioural disturbance: a UK national survey of rapid tranquillisation. Journal of Psychiatric Intensive Care 1: 84-8.

Petit J (2005) Management of the acutely violent patient. Psychiatric Clinics of North America 28: 701-11.

Pfizer (2009) Highlights of Prescribing Information: Geodon (Ziprasidone HCL) Capsules, Geodon (Ziprasidone Mesylate) Injection for Intramuscular Use. Product Information, Revised May (http://www.pfizer.com/files/ products/uspi_geodon.pdf).
Preval H, Klotz SG, Southard R, et al (2005) Rapid-acting intramuscular ziprasidone in the psychiatric emergency service: a naturalistic violence. General Hospital Psychiatry 27: 140-4.

Raja M, Azzoni A (2001) Novel antipsychotics and acute dystonic reactions. International Journal of Neuropsychopharmacology 4: 393-7.

Raja M, Azzoni A (2003) Comparison of three antipsychotics in the emergency room setting. Human Psychopharmacology 18: 447-52.

Ray WA, Meredith S, Thapa PB, et al (2001) Antipsychotics and the risk of sudden cardiac death. Archives of General Psychiatry 58: 1161-7.

Tran-Johnson TK, Sack DA, Marcus RN, et al (2007) Efficacy and safety of intramuscular aripiprazole in patients with acute agitation: a randomized, double-blind placebo controlled trial. Journal of Clinical Psychiatry 68: $111-9$.

TREC Collaborative Group (2003) Rapid tranquillisation for agitated patients in emergency psychiatric rooms: a randomised trial of midazolam versus haloperidol plus promethazine. BMJ 327: 708-11.

Tulloch KJ, Zed PJ (2004) Intramuscular olanzapine in the management of acute agitation. Annals of Pharmacotherapy 38: 2128-35.

Van Schaick EA, Lechat P, Remmerie BM, et al (2003) Pharmacokinetic comparison of fast-disintegrating and conventional tablet formulations of risperidone in healthy volunteers. Clinical Therapeutics 25: 1687-99.

Villari V , Rocca P (2008) Oral risperidone, olanzapine and quetiapine versus haloperidol in psychotic agitation. Progress in Neuro-Psychopharmacology and Biological Psychiatry 32: 405-13.

Wise $\mathrm{R}(2000)$ New restraint standards will change your practice. ED Management 12: 93-5.

Wright P, Birkett M, David SR, et al (2001) Double-blind, placebo controlled comparison of intramuscular olanzapine and intramuscular haloperidol in the treatment of acute agitation in schizophrenia. American Journal of Psychiatry 158: 1149-51.

Wright P, Meehan K, Birkett M, et al (2003) A comparison of the efficacy and safety of olanzapine versus haloperidol during transition from intramuscular to oral therapy. Clinical Therapeutics 25: 1420-8.

Yudofsky SC, Kopecky HJ, Kunik M, et al (1997) The Overt Agitation Severity Scale for the objective rating of agitation. Journal of Neuropsychiatry and Clinical Neurosciences 9: 541-8.

Zimbroff DL, Marcus RN, Manos G, et al (2007) Management of acute agitation in patients with bipolar disorder: efficacy and safety of intramuscular aripiprazole. Journal of Psychopharmacology 27: 171-6.

\section{MCQs}

Select the single best option for each question stem

1 The pharmacological agent that has demonstrated particular efficacy in managing hostility/aggression in agitation is:

a risperidone

b midazolam

c lorazepam

$\mathrm{d}$ quetiapine.

\section{The pharmacological agent with quickest} onset of action is:

a olanzapine

b risperidone

c lorazepam

d midazolam.
3 The first step in managing acute agitation should be:

a prepare intramuscular haloperidol and lorazepam

b physically restrain the patient

c offer patient oral risperidone

$\mathrm{d}$ isolate patient from other patients.

4 Which of the following has the greatest potential to increase psychosis and/or worsen agitation?

a lorazepam

b midazolam

c diazepam

d clonazepam.
5 Which class of pharmacological agent should be avoided in patients who are being given olanzapine?

a selective serotonin reuptake inhibitors

b typical antipsychotics

c benzodiazepines

d fluoroquinolones. 